\section{Alzheimer's disease and the family effect}

Sir-Van Duijn et al. ${ }^{1}$ reported in the May 1994 issue of Nature Genetics that both the number of $\varepsilon 4$ alleles in the apolipoprotein $\mathrm{E}$ (apoE) genotype and a family history of a first-degree relative with memory problems influence risk of early-onset Alzheimer disease (EOAD), in a population-based sample. However, their data do not demonstrate that family history modifies the apoE genotype effect. Such modification, statistical interaction, would mean that the effect of family history is not the same for all genotypes. When logistic regression is used to formally test for a statistically significant interaction in their data, interaction can be rejected ( $p=0.65$, or $p=0.38$ if the small number of $\varepsilon 4 \varepsilon 4$ individuals are excluded). There are highly significant additive effects of both family history $(p=0.0001)$ and number of apoE $\varepsilon 4$ alleles ( $\mathrm{p}=$ 0.0001 ). Given recent evidence that the 22 allele modifies $\mathrm{AD}$ risk, pooling the genotypes by number of $\varepsilon 4$ alleles is contraindicated and could mask some types of interaction ${ }^{2}$. Whether these two factors act additively or interact in the prediction of $\mathrm{AD}$, has important implications on the patho-physiologic mechanisms at work. We have presented evidence that family history and apoE genotype interact in the prediction of $\mathrm{AD}$ in a primarily late onset (LOAD), population-based sample ${ }^{3}$. The contradictory results in EOAD and LOAD are consistent with an aetiologic difference between these two groups.

Gail Pairitz Jarvik

Ellen M. Wijsman

Division of Medical Genetics

University of Washington

Mail Stop RG-25

Seattle, Washington 98195

IN REPLY - Jarvik and Wijsman argue that our data do not show evidence for modification, by family history, (FH) of the effect of the Apolipoprotein $\varepsilon 4\left(\mathrm{APOE}^{\star} 4\right)$ genotype on the risk of $\mathrm{EOAD}^{1}$. Absence of such an effect contrast with their observation in late-onset Alzheimer's disease (LOAD) and may underlie aetiological differences between EOAD and LOAD.

Their argument is based on the results of the statistical tests for interaction which are indeed nonsignificant. However, lack of statistical significance should be interpreted with caution because of the limited statistical power ${ }^{4-6}$. Given our finding of a 1.6 fold increase in risk of EOAD associated with the $\mathrm{APOE}^{\star} 4$ genotype in those with a positive $\mathrm{FH}$ as compared to those with a negative $\mathrm{FH}$, a population of more than 1,000 patients and controls is needed to reject the hypothesis of no interaction with a probability of $95 \%$.

To increase the statistical power, we have reanalysed our data adding 373 age-matched control subjects derived from another Rotterdam population-based study ${ }^{\gamma}$. This analysis did not change any of our initial conclusions ${ }^{1}$. For the $\mathrm{APOE}^{*} 4$ heterozygotes with a positive $\mathrm{FH}$, a significant increase in EOAD risk was found, but not in those with a negative FH (OR 1.3;95\% confidence interval 0.7-2.3). The risk of EOAD for the $\mathrm{APOE}^{\star} 4$ homozygotes was always significantly increased. The effect of the $\mathrm{APOE}^{\star} 4$ allele and $\mathrm{FH}$ was nonadditive $(\mathrm{p}=0.03)$, confirming effect modification. Also, in both homozygotes and heterozygotes the risk for those with a positive $\mathrm{FH}$ was 1.6 times increased compared to those with a negative $\mathrm{FH}$.

Our new data indicate that there is no evidence for differences between EOAD and LOAD with respect to $F H$ modifying the APOE genotype effect.

\section{C. van Duijn}

Department of Epidemiology

\& Biostatistics,

Erasmus University Medical School, 3000 DR Rotterdam

The Netherlands

\section{Van Broeckhoven}

Laboratory of Neurogenetics, Born Bunge Foundation University of Antwerp (UIA), 2600 Antwerpen

Belgium

1. van Duijn et al. Nature Genet. 7, 74-78 (1994)

. Jarvik, G.P. et al. Neurology (in the press)

3. Jarvik, G.P. et al. Genet. Epidemiol. (in the press).

4. Smith, P.G. \& Day, N.E. Int. J. Epiderniol. 13, 356-365 (1984).

5. Breslow, N.E. \& Day, N.E. IARC Scientific Publications, No. 32 (1980)

6. Rothman, K.J. Modern Epidemiology (Little, Brown and Co., Boston, 1986).

7. Hofman, A., Grobbee, D.E., DeJong, P.T.V.M 8 Vandenouweland, F.A. Eur. J. Epidemiol. 7 , 403-422 (1991).

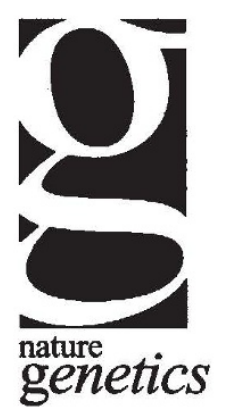

Subscription information, Table of Contents and selected abstracts are available on-line on the first day of each month through the Electronic Newsstand.

On the internet:

gopher to gopher.internet.com or telnet to gopher.internet.com and login as enews 